\title{
Proceeding
}

Supplementary Issue: Summer Conferences of Sports Science. Costa Blanca Sports Science Events, 20-21 September 2019. Alicante, Spain.

\section{About how educational dance course may be crucial in school age children's psycho-motor development}

\author{
CARMEN PALUMBO, LUCIA PALLONETTO , ANTINEA AMBRETTI \\ Department of Human Sciences, Philosophy and Education, University of Salerno, Italy
}

\begin{abstract}
Numerous studies have shown that children- aged between 5 to12 are able to develop artistic-sporting motor skills, which can be attributed in particular to general coordination and balance. They may be indicators of psychomotor development (Le Boulch, 1992). The possible use of motor test batteries in educational contexts (Vayer, 1992) allows to obtain fundamental information on the level of children initial motor maturation as well as to acquire objective data on circumstances relevant to the possible identification of evolutionary levels through a standardized process for measurement and analysis (Meinel, 1984) guiding the planning of individualized didactic activities. Among the numerous batteries present on an international scale, the Oseretzky-Guilmain test could be considered among evaluation tools for the possible detection of the psychomotor age, referring in particular to three categories such as: "balancing" on one leg; "staying" with your eyes closed on your toes and "jumping" on one leg. The Salerno research group conducted a field research involving a sample of 320 children, aged $6-8$, whose one only half practicing sport (dance), who were given Oseretzky-tests Guilmain. It has been shown that children accustomed to sport- dance in our study case - pass the above tests far much easier than those ones not doing any physical exercises. Furthermore, their chronological age matches undoubtedly their psycho-motor one (Oseretzkj 1931- 36). It follows that it would be useful for the school to point to a constant reference to sporting activities from the earliest years of schooling. Keywords: Educational dance; Psyco-motor; Test Oseretzky - Guilmain.
\end{abstract}

Cite this article as:

Palumbo, C., Pallonetto, L., \& Ambretti, A. (2019). About how educational dance course may be crucial in school age children's psycho-motor development. Journal of Human Sport and Exercise, 14(5proc), S2000-S2008. doi:https://doi.org/10.14198/jhse.2019.14.Proc5.21

Corresponding author. Department of Human Sciences, Philosophy and Education, University of Salerno, Italy.

E-mail: Ipallonetto@unisa.it

Supplementary Issue: Summer Conferences of Sports Science. Costa Blanca Sports Science Events, 20-21 September 2019. Alicante, Spain.

JOURNAL OF HUMAN SPORT \& EXERCISE ISSN 1988-5202

(c) Faculty of Education. University of Alicante

doi:10.14198/jhse.2019.14.Proc5.21 


\section{INTRODUCTION}

The programming of possible operational proposals aimed at constructing the constituent elements of general coordination and equilibrium constitutes, in the educational field, one of the main problems of teaching directly correlated to the difficulty on the part of teachers especially of kindergarten of being able to plan possible ad hoc didactic tracks.

Even today, in the Italian school too often the teachers slip into the temptation to propose rigid and static activities that would aim at achieving national ministerial goals, too often unrelated to the reality and specificity of the class context to which they should be addressed and programmed.

In the programs and in the Guidelines of the Italian Ministry of Education (Miur, 2012) a specific dimension of coordination and balance has been introduced which refers to the static and dynamic relationship of one's own body with respect to the surrounding environment or the ability to integrate the anatomical and functional characteristics of the body and with specific and synchronic actions stimulated by stimulations coming from the environment of everyday school life.

This specific ability to coordinate the information obtained from the various sensorial modalities can be defined as the expression of a constant cognitive and social integration that characterizes the "motor system and in particular that part which is expressed in the posture ..."; the execution of "increasingly concrete and precise gestures" depends on a complex system of interactions between visual and proprioceptive information aimed at planning the movements of the body according to a personal capacity to "represent the movements to be performed and to give them an order of succession a direction relative to the identification of the positions of the parts of one's own body".

According to Berthoz the general coordination, with reference to the "complexity of the coordinative tasks" that engage the whole body and its segments in an incessant regulation activity, is inserted as a requirement of "realization of multiple references related to the different parts of the body" allowing a synergy of tactile and visual elements that direct the movements.

The ability to control and harmonize one or more movements both in terms of effectiveness and continuity is in fact connected to a series of factors that are also determined by the specific phase of growth, maturation and development of the different systems that regulate movement, by diversity physical and mental characteristics of the subject and the characteristics of his cognitive system.

Meinel in this regard clarifies that the conditions of the coordinated action are reflected in the "... functional capacity (functional maturity) of the movement control bodies ... .." to receive, process and transmit information from the environment by developing its own functionality in relation to the typology of diversified experiences whose quality depends on "... morphological and functional presuppositions existing in the organism and in its organ systems." accompanied by "return information".

In this sense childhood, characterized by specific phases of the processes of functional maturation and psychomotor development, is configured as a period in which only a few motor tasks can be performed, as each motor execution is also linked to the possible motor control capacity. 
In this perspective, coordination would depend both on the development phase and on the function of the environment in offering the subject executive opportunities and building motor skills. It becomes essential, during the transition from nursery school to primary school, to intervene educationally.

On those movements that are not very fluid, characteristic of the raw coordination typical of early childhood, in this sense it gradually evolves thanks to the regulatory influence of the environment, allowing the child to act more consciously, urging "not a simple automatic repetition of the movement" but a personal one processing of sensory information. The execution of increasingly precise and functional movements to the realization of a specific action takes shape progressively thanks to the synergic functionality of the visual channel with the movement of the body and its parts; in this sense the dance and the movements that it solicits, in Meinel's view, could assume the task of constructing on the basis of sensations and perceptions the premises for the full development of cognitive processes and that is why, regardless of the level of school, each segment school has the task of offering captivating proposals that can effectively leverage the solicitation of the coordinated movement aimed at achieving a goal.

The gradual refinement of "movements at first brusque and broken" takes place in relation to anatomicalfunctional and cognitive evolutions "that can develop fully only on the basis of very different sensations and perceptions".

The integration of the combined movements prompted by the dance would be indicative of "a motor action related to an object that can no longer be considered a simple body movement"; in this sense the development of intellectual processes is configurable as the "transformation of processes that were originally directed to external objects in the form of motor actions".

An operational proposal that aims to leverage the objectives, tools and methodologies appropriate "to the age, motor experiences and knowledge of his students" can only be deviant.

In reality, in the latest ministerial indications, reference is continually made to this principle, implicitly describing it as an element underlying the teaching responsibility of teachers. In the various sections of the national indications for the curriculum of the primary teachers are invited above all to experiment and search for alternative didactic itineraries urging the teachers themselves to abandon the rigidity of safe didactic proposals already calibrated over the years during their personal teaching experience and devote themselves to in search of deviant itineraries for the definition and the programmatic choice of objectives, for the learning and development of "new movements", starting from the analysis of the motor assumptions that "are reflected in the level of coordination skills and movement skills already existing ....".

The possible use of motor test batteries in educational contexts (Vayer, 1992) allows to obtain fundamental information on the level of children initial motor maturation as well as to acquire objective data on circumstances relevant to the possible identification of evolutionary levels through a standardized process for measurement and analysis(Meinel, 1984) guiding the planning of individualized didactic activities.

Among the numerous batteries present on an international scale, the Oseretzky-Guilmain test could be considered among evaluation tools for the possible detection of the psychomotor age, referring in particular to three categories such as: "balancing" on one leg; "staying" with your eyes closed on your toes and "jumping" on one leg. 
The Salerno research group conducted a field research involving a sample of 320 children, aged 6 -8, whose one only half practicing sport (dance), who were given Oseretzky-testsGuilmain.

It has been shown that children accustomed to sport- dance in our study case - pass the above tests far much easier than those ones not doing any physical exercises. Furthermore, their chronological age matches undoubtedly their psycho-motor one (Oseretzkj 1931-36).

\section{METHOD}

The objective of the research work was to assess the balance, through suitable tests performed on fourth and fifth grade students, in particular through the Oseretzky-Guilmain test (OSERETZKY N.A., 1948).

The present research is configured as a field study, of a qualitative and quantitative nature. Based on the various responses of the children to the battery of the test, they are assigned a score that we will have to record to then rework.

The tests were carried out in a school classroom, in the presence of three female researchers and were first explained and presented to children as a game, albeit a game of balance, always giving the sample the time needed to make him feel ready and at ease.

During the execution it was appropriate to encourage the child to maintain the required position.

Each test is repeated three times in order to obtain the best result, which is what is then evaluated. A short recovery time of about 10 seconds was left between one trial and another.

It should be remembered that at the base of the test in question, there is another that is what is needed for the psychomotor assessment, without which we would not have the necessary starting point and that gave us information regarding the balance abilities evaluated both from the point of view quantitative, both from the qualitative point of view, that is from the habits and characteristics observed in the child.

\section{Sample}

The Salerno research group conducted field research involving a sample of 320 children between 6 and 8 years old, of whom 160 who play sports (dance) and 160 who do not practice sports, who were given the Oseretzky-Guilmain test, of which the two most significant types of tests were mainly used, which are aimed at assessing the psychomotor age of children and therefore indicate, in the case of non-correspondence whether it is necessary to intervene to correct any delays or minor disturbances of various kinds (Lucangeli 2006).

\section{Instruments}

The two tests administered are:

a) Balance test;

b) General dynamic coordination test.

Let's focus on the balance test.

a) Two tests were included in the balance test. 
In the first one, the children were asked to stay balanced on one leg, keeping the other flexed against the knee of the stretched one. The arms: one stretched along the side and the other with the hand resting on the bent knee. This test must be performed 3 times for at least 10 seconds, during which it is important to observe if and which errors the subject makes. Possible mistakes are: losing your balance, opening your arms, not being able to keep your foot on your knee for as long as required, changing the position of your leg. In the second test, the children must remain with their eyes closed, not bandaged, keeping their balance on their toes, with their arms at their sides and their feet together. Also, this test must be performed 3 times for at least 10 seconds, during which it is important to observe if and which errors the subject makes. Possible errors are: spread the arms, open the eyes, swing excessively, change the weight of the body.

\section{Research plan}

This test is used as a basis for the design of individualized itineraries and educational progressions that can, on the one hand, reinforce the skills possessed and on the other hand develop those not yet available. It is therefore more destined to the educational and didactic field and is composed of different tests that compare the outcome of the same with the chronological age and with the competences expected at that age. It is an excellent test that allows to evaluate the psychomotor age of children in relation to the actual chronological age.

\section{Data emerged}

Through data collection it was possible to see that among the children who do not practice sports in the Equilibro test only 69 out of 160 pass the test, therefore 91 out of 160 do not pass the test.

Instead among the children who practice sports, in this case the dance, at the Balance Test 112 out of 160 they pass the test, therefore 48 out of 160 do not pass it.

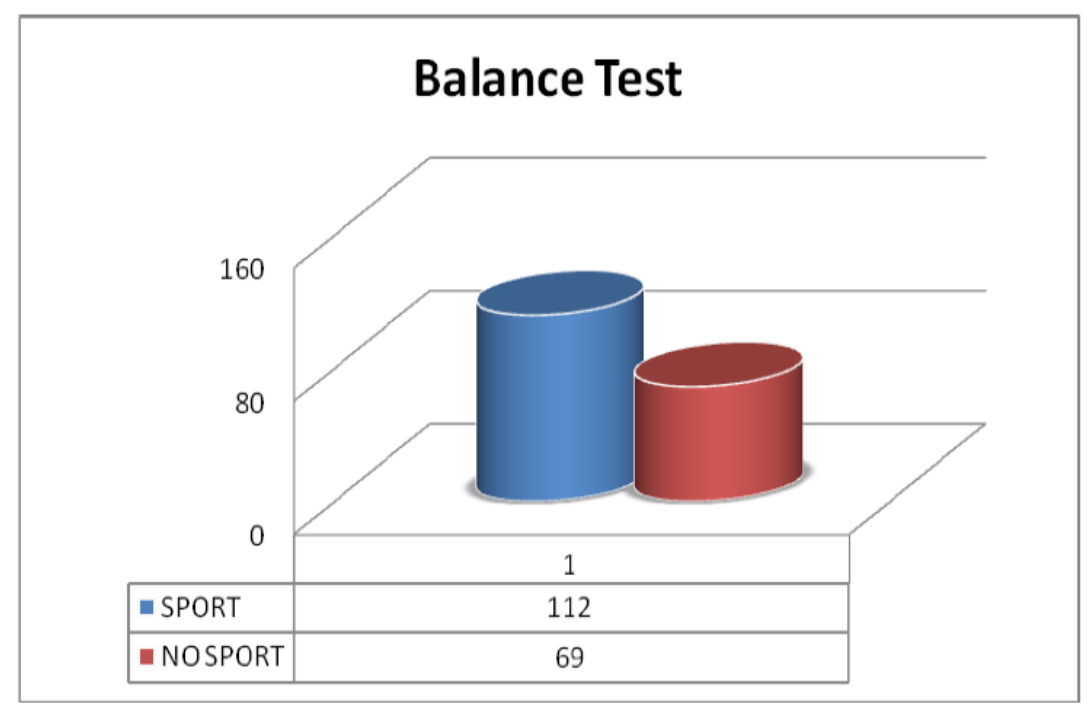

Figure 1. Balance test. 


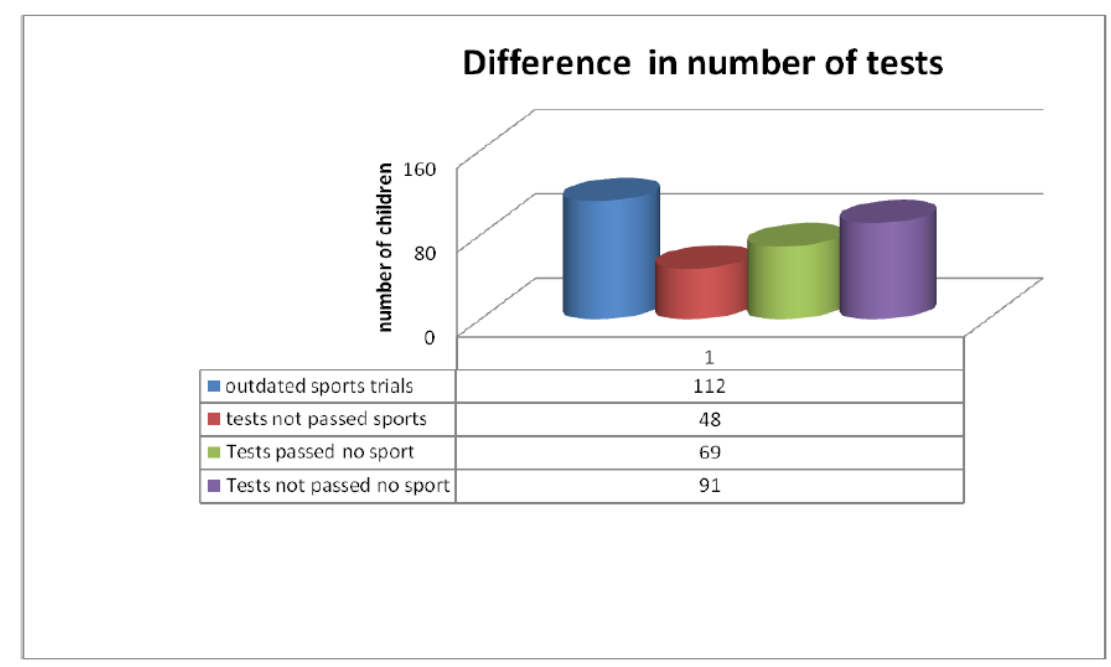

Figure 2. Difference in number of tests.

\section{RESULTS}

After the test was administered, the results were reported in percentage form using graphs, applying a simple arithmetic average and comparing the two groups of children in the Balance test.

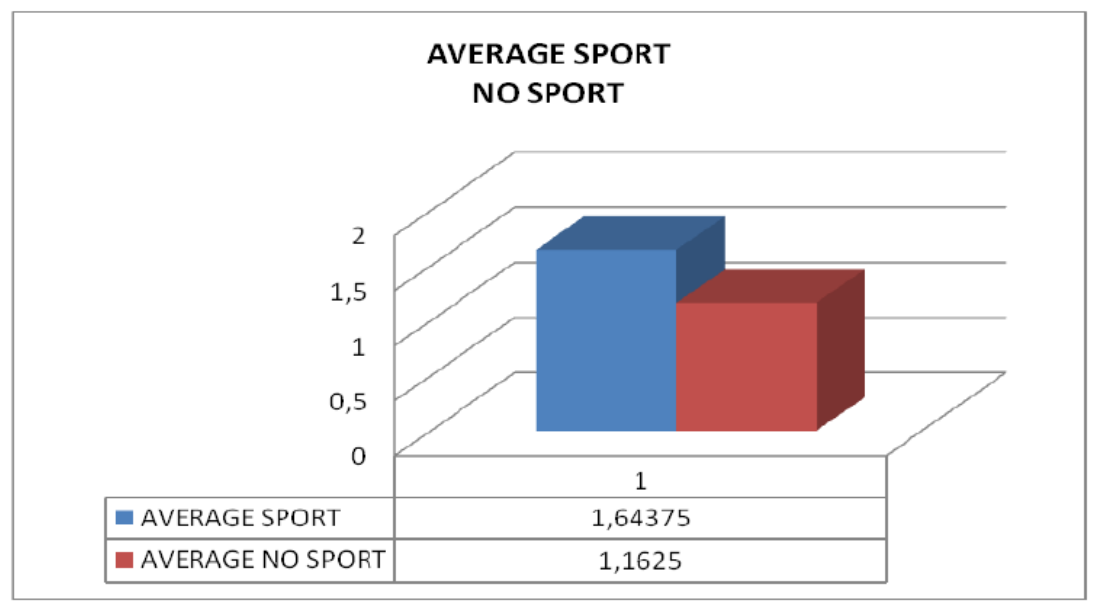

Figure 3. Average sport - no sport.

To all this a small change has been made, adding a degree of difficulty: according to Oseretzky - Guilmain the positive result is obtained only when 1 test out of 3 succeeds, instead the positive result required was evaluated when 2 tests out of 3 were successful, because it is it emerged that it was too easy a goal for children who habitually dance.

So, the significant result is that children accustomed to movement - dance pass balance tests much more easily than others.

After this premise we can see, as the graph shows, that in the Balance test $70 \%$ of children who practice sport, in this case dance, have passed at least 2 out of 3 tests, while only $43 \%$ of children who do not practice sports have passed the test. 


\section{Balance test}

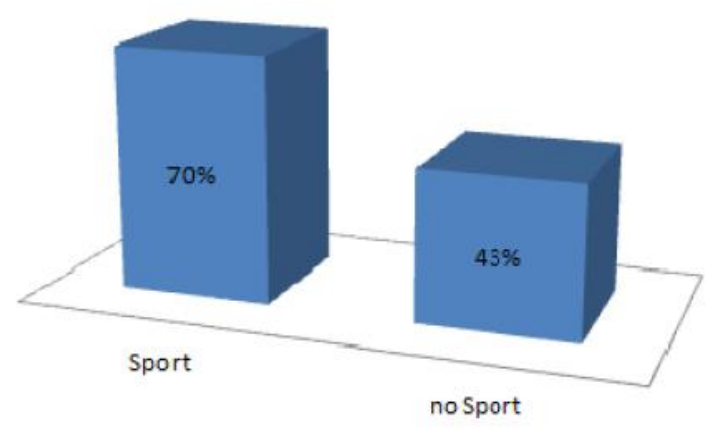

Figure 4. Balance test.

\section{CONCLUSIONS}

During the test we found a curious, unexpected and yet evident fact.

The children tested also having the same age did not have the same facility to learn the instructions given to carry out the test itself.

Some even struggled to distinguish or name the right rather than the left.

The really interesting fact was that this difficulty only concerned children who do not practice dance.

Therefore the main result is that the educational dance, besides contributing to a better use and to a possible improvement of the motor skills, is a particularly suitable and useful tool, in some cases perhaps necessary, to the development of all the dimensions of the personality and also of some primary skills, actively and alternatively favouring the learning processes and not only the physical ones.

All this brings down the old cornerstone that emphasized the mind-body dichotomy, demonstrating that the body is inclusive and above all that its correct stimulation through a meditated physical activity can favour the intertwined growth of the physical universe and the mental universe of a young person.

The educational dance is in itself integrative, not only when it is therapeutic, but every time it becomes an opportunity for recognition of one's identity and potential, thus generating the ability to give clear signals to the outside and increasing capacity / learning ability, because it allows you to exercise them and verify them in a rapt and indispensable way for a good execution.

The young man, through the dance movement, is naturally induced to notice that one movement rather than another, a step taken with the right rather than a step taken with the left generate:

1. The success of the test (therefore the correct effect);

2. In oneself and in those who are outside, emotions strictly connected to the surrounding space, to the music heard and to its rhythm and, where present, to the other subjects of one's group. 
The educational dance thus allows to develop a correct movement but also in a creative form, giving the possibility of externalizing the conscious expression of what is represented and animated in each one and offering an additional possibility not only to express oneself but also to communicate in an effective and controlled way with the world surrounding the child.

Reading the most important acts on the subject of regulations concerning the use of dance-education as a didactic activity in primary school and kindergarten, we discover a new awareness of dance as an educational possibility and therefore a concrete predisposition of the School towards the insertion of the dance movement as a discipline and a new chance to facilitate psychophysical growth.

Through the elaboration of projects that confirm the didactic-movement-creativity link, it is possible to arrive at the definitive confirmation of the validity of an educational vision of corporeity as the main support for intellectual and creative development.

The habit of psychophysical effort requires on one hand a constant training, which in the School is possible, given the daily frequency and on the other hand a space large enough (a room, a classroom, a gym) where to practice it and where to use music, which is not only a formative aspect but also a playful one, which makes the job more fun for the young person learner.

In the context of physical activities, therefore, the educational dance should also be favoured for the added value given by the creativity that stimulates, the use of music and the intrinsic spectacularity.

\section{REFERENCES}

Ambrosini, C., De Panfilis, A., Wille, M. (1999). Psychomotility. Corporeality and action in the construction of identity. Xenia edition.

Argyle, M. (1984). The body and its language, Zanichelli, Bologna.

Aucouturier, B., Darrault, I., Empinet, J.L. (2009), The psychomotor practice.

Bruner, J. (1971), "First phases of cognitive development", Rome, Armando Ed.

Cools, W., De Martelaer, K., Samaey, C., Andries, C. (2009), "Movement skill assessment of typically developing preschool children: A review of seven movement skill assessment tools", Journal of Sports Science and Medicine 8. https://doi.org/10.1080/02640414.2010.551540

Coste, J. C. (1981). Psychomotility. Florence: The new Italy.Coste, J.C. (1997). Psychomotricity, La Nuova Italia, Florence.

Duncan, I. (1992). "The dance of the future", cit. in A.A.V.V.

Formenti, L. (2010), Psychomotricity at school, Erickson, Trento.

Gaiffi, S. (1987). The body, in: Motor education. Teacher knowledge, skills and abilities.

Giugni, G. (1986). The body and movement in the educational process of the person. Torino. Gomez Paloma, F. (2004). Corporeity and emotions. A psychomotor training for knowing ... being. Alfredo Guida Editore.

Lapierre, A. (2002). From relational psychomotor to body analysis of the relationship. Armando Editore. Rome.

Le Boulch, J. (1992). Psychomotor development from birth to six years. Educational consequences of psychokinetics in school age.

Meinel, K. (1984). Theory of movement. Sports Press Company, Rome.

Morin, E. (1993). Knowledge of knowledge. Milan. 
Oseretsky, N.I. (1936). The metric scale of development of motor skills in children and adolescents. Higyene Mental.

Palumbo, C. (2013). Educational dance: educational dimensions and educational perspectives, Anicia, Rome.

Palumbo, C. (2018). The Inclusive Body - Education, expressiveness and movement. Edises.

Piaget, J. (1973). The birth of intelligence in children, Milan.

Piaget, J. (2000). Mental development of the child: and other psychology studies. Lathe. Einaudi Rome: Armando publisher, p. 39. Unicopoli school, p. 15.

Sachs, C. (2006). "History of dance". The Milan Assayer.

Vayer, P. (1992). Psychomotor education in the school age.

Vayer, P. (2000). Psychomotor education in the school age. Rome: Armando.

\section{(c) (i) ()}

This work is licensed under a Attribution-NonCommercial-NoDerivatives 4.0 International (CC BY-NC-ND 4.0). 